\title{
Model-Based Dynamic Structural Modification of Machine Tools
}

\author{
Mateusz Wąsik (D), ${ }^{1}$ Krzysztof Lis, ${ }^{1}$ Krzysztof Lehrich, ${ }^{1}$ and Lukasz Mucha ${ }^{2}$ \\ ${ }^{1}$ Silesian University of Technology, Machine Technology Department, Poland \\ ${ }^{2}$ Foundation of Cardiac Surgery Development, Biocybernetics Laboratory, Poland \\ Correspondence should be addressed to Mateusz Wąsik; mateusz.wasik@polsl.pl
}

Received 11 November 2017; Accepted 2 May 2018; Published 30 May 2018

Academic Editor: Jussi Sopanen

Copyright (C) 2018 Mateusz Wąsik et al. This is an open access article distributed under the Creative Commons Attribution License, which permits unrestricted use, distribution, and reproduction in any medium, provided the original work is properly cited.

\begin{abstract}
The article proposes modification of machine tool structures methodology on the example of a body of vertical milling centre stand. It is based on the results of experimental research and allows for the prediction of dynamic features of individual bodies and complete structures on the basis of the described modal model. It takes into account the possibility of mass change at the model node and the introduction of additional rigidity and damping by a combination of selected nodes of the model. The methodology can be applied in the case of machine tools in which the loss of stability has been found during its maintenance, what consequently disables the possibility of machining with the required machining parameters from the performance point of view. Modal parameters modification is based on structural dynamic modification techniques and preliminary simulation tests performed by using Finite Element Method (FEM) and verification with experimental research.
\end{abstract}

\section{Introduction}

The dynamic properties of machine tools have a very significant impact on the process of cutting and are considered among the most important features of the assessment of the machine construction. They are often described with the characteristics of frequency resources that allow assessing the stability of the machine and the cutting process $[1,2]$. The dynamic properties can determine the surface roughness, control, and the emitted noise. Analysis of the dynamic properties of machine tools support structures should be one of the major steps taken in the construction of the machine. At the design stage, for this purpose, Finite Element Analysis (FEA) and a virtual model can be used, which is the base of the development of construction documentation. FEM application does not give a full and accurate description of the dynamic properties of the machine structure, which is a result of multiple contact connections in guiding systems and between individual bodies of the machine that are often not considered in FEM simulations [3-6]. Therefore, it is reasonable to analyse the dynamic properties of machine tools experimentally (e.g., by carrying out an experimental modal analysis). In this case, a physical model is required. This approach generates a need for constructing a prototype, which is not always possible. For example, in comparison to the heavy machine tools, it is not practiced due to high costs and tight times of the contract. In case of machine tools, mass-produced construction of the prototype is well founded and (depending on the applied test method) allows obtaining some more or less complete information about the examined object.

The article proposes modification of machine tool structures methodology. It is based on the results of experimental research and allows for the prediction of dynamic features of individual bodies and complete structures on the basis of the described modal model. It takes into account the possibility of mass change at the model node and the introduction of additional rigidity and damping by a combination of selected nodes of the model.

\section{Materials and Methods}

2.1. Subject of the Study. The tests were carried out on machine bodies of shapes and dimensions obtained in the optimisation process. [7]. The study was conducted shortly after manufacturing the body on a temporary experimental station. The analysed body is a part of a research and teaching station developed in the Machine Technology Department at 


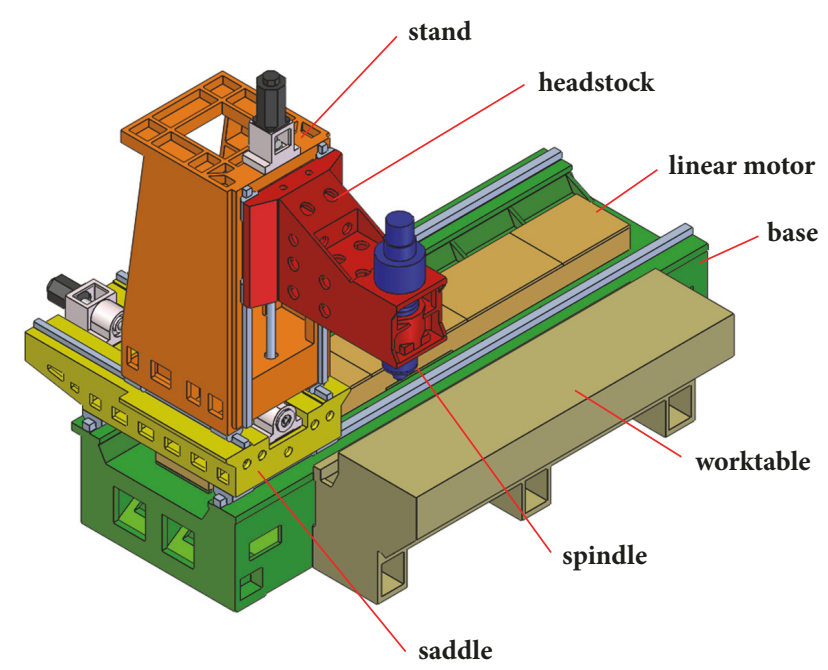

FIgURE 1: CAD model of the analysed milling centre.

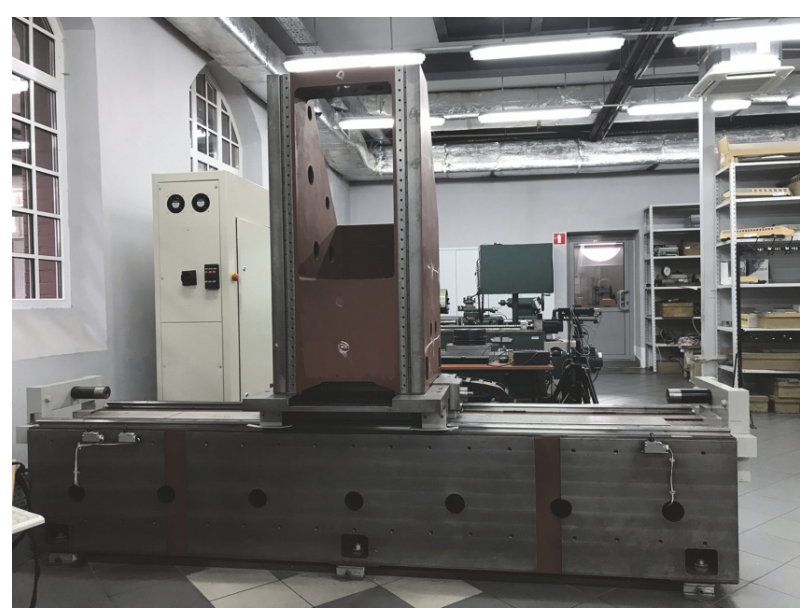

FIgURE 2: Prototype of the machining centre.

the Silesian University of Technology [8-10]. In the original design proposed by the constructors, the analysed bodies were elements of the support structure of the milling centre (Figure 1). An exemplary machine (Figure 1) includes 3 moving bodies (headstock, stand, and saddle) driven by individual motors. For those bodies, some specific demands are needed, among other high dynamic properties-high accelerations in transient states (up to $1 \mathrm{G}$ ). For this reason, it is important to designate the dynamic properties of the machine of moving bodies.

The stand body is casted from cast iron. Milling centre bodies, like most of the machine tools bodies, are characterised by dense internal ribbing. The prototype of the machining centre (Figure 2) comprises a plurality of moving (sliding) and fixed bodies (Figure 1). From the possible configurations of the spatial region, a work area (area in the form of a cuboid) is created, within which the machining can be carried out. In the analysed case, only the extreme position of the mill stand has been considered. Based on the models of individual geometric bodies (3D models) proposed

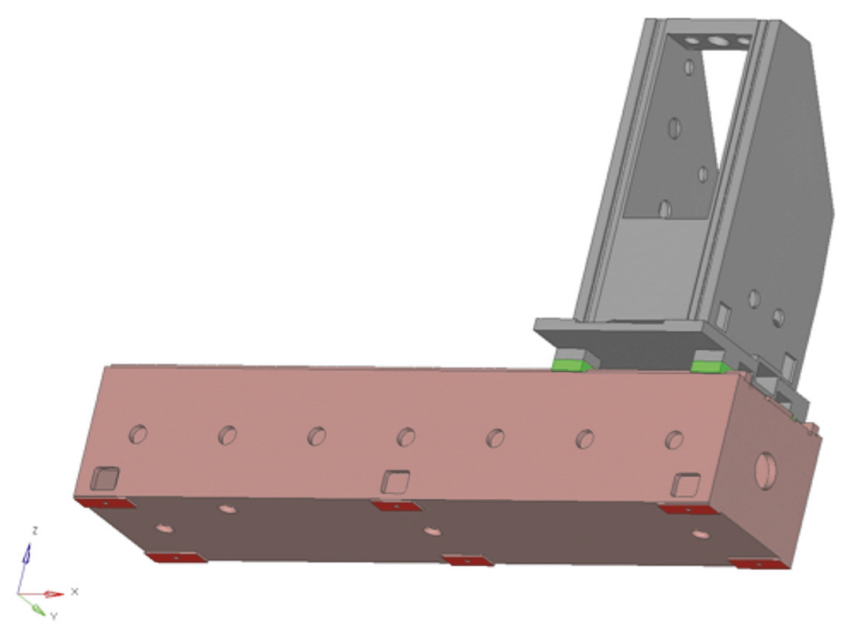

FIGURE 3: FEA model of the analysed milling centre's stand and base.

by an experienced designer, the numerical models for a finite element analysis have been developed. Figure 3 pictures the numerical FEM model developed for the conducted research. The simulation tests were carried out using ANSYS software. For model discretisation, solid elements were used, predominantly octagonal elements. At the experimental temporary station, the stand body is connected with the base with sliding joint. Therefore, in the FEM model for the connection between the base and the stand spring elements were used (marked green in Figure 3) with damping parameters selected in optimisation with genetic algorithms as described in $[7,9]$. The base body is bolted to a steel plate placed under the steel frame that represents rigid ground, so the base received all degrees of freedom. Fixing points are marked red in Figure 2. Obtained results were validated by analysing the result change due to the mesh size change. The model was regarded as correct when the further decrease of the FEM mesh size does not significantly change the obtained results.

\subsection{Experimental Tests for the Evaluation the Modal Parame-} ters. In order to evaluate the frequency and normal modes, verification tests were carried out by using experimental modal analysis based on the principle of Maxwell's reciprocity. The extortion in this method is a pulse generated by a modal hammer; the response is recorded using a threeaxis acceleration sensor. The analysed milling centre body was marked with grid points that represent extortion points (Figure 4). During the study, the modal sensor is positioned at one selected point and the modal hammer hits sequentially all of the points. The experiment was conducted by analysing the forms of vibrations of available body parts. The milling centre stand is box-shaped, so the measuring grid for the stand is regular in both directions ( $X$ and $Y$ ) with spacing of $21 \mathrm{~cm}$. The arrangement of measurement points for the mill stand is shown in Figures 4(a), 4(b), and 4(c). The milling centre stand is box-shaped with one dimension much larger than the other (long and narrow element), so the measuring grid for the mill base is irregular in both directions ( $X$ and $Y$ ). The arrangement of measurement points for the mill base 


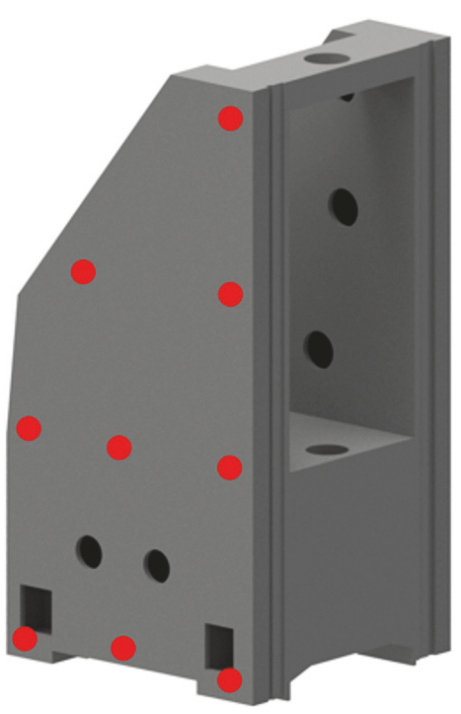

(a)

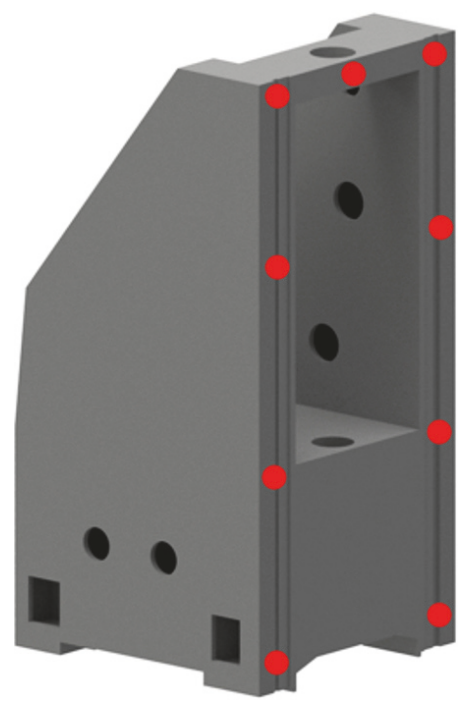

(b)

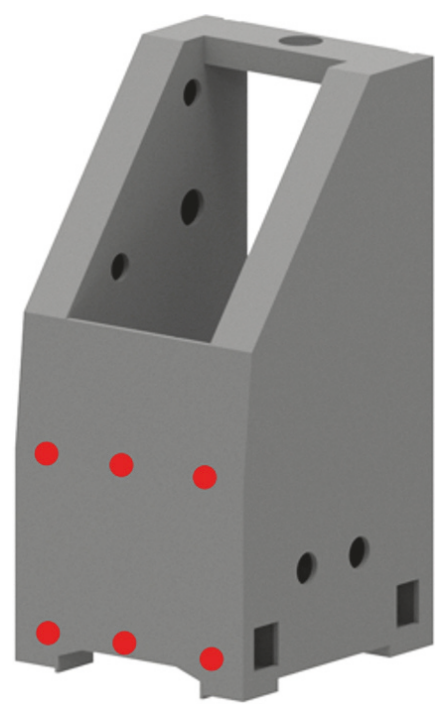

(c)

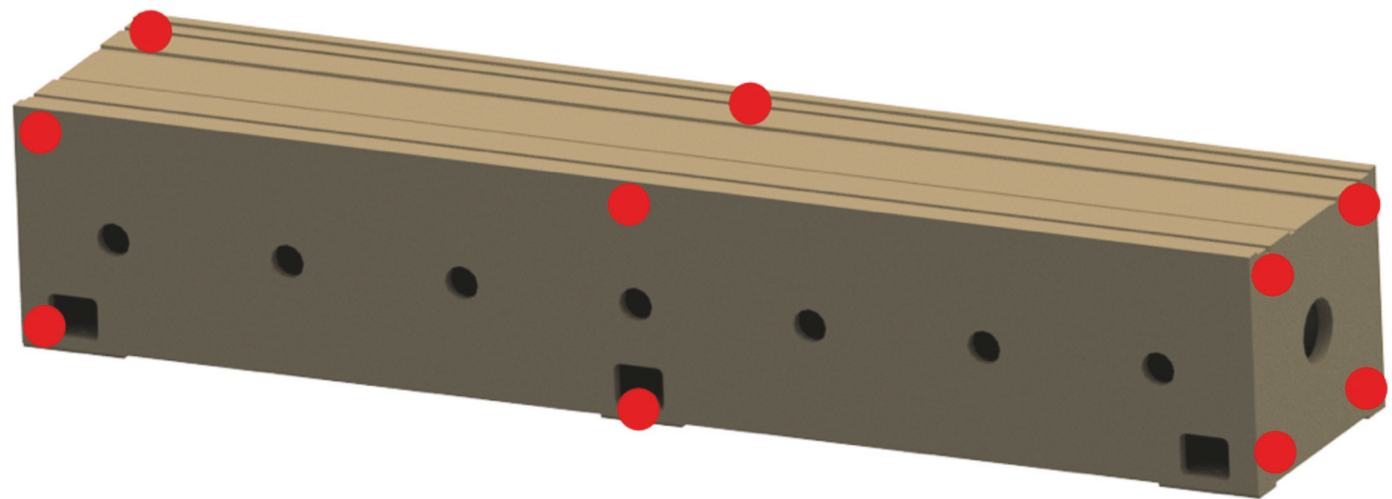

(d)

FIGURE 4: Position of measurement points on the bodies of column: (a) side wall, (b) front wall, (c) back wall, and (d) base.

is shown in Figure 4(d). The tests were performed in three stages by analysing vibration forms in sequence: the side wall and the front and rear of the body. In the extortion, the PCB Piezotronics 086D20 modal hammer (approx. 1 kg) equipped with a tip of medium hardness with a band of extortion up to $700 \mathrm{~Hz}$ was used. The answer was recorded with the use of a measuring circuit, consisting of a triaxial accelerometer (3x PCB 353B15) and a card NI PXI 4472B for measuring the vibrations. The data acquisition uses a measuring computer with dual-core controller module NI PXI-8108 in National Instruments NI PXI- 1042 housing. ModalVIEW was applied in order to carry out the modal experiment. The research system was developed within the framework of the work done in the development project conducted in the Machine Technology Department at the Silesian University of Technology. The verification tests were carried out using experimental modal analysis [11-15] in order to evaluate the frequency and normal mode forms. Modification Techniques. Modification prediction technique allows evaluating structural modifications of elements such as mass, spring-damper, and tuned absorber on the dynamic behavior of a mechanical structure. The modification prediction structural analysis software uses modal system synthesis techniques. Model of the modified structure can be calculated based on the modal model (scaled mode shapes identified with experimental or finite element modal analysis) and on the modification element definition modal. At the software level that requires as input FEM or experiment modal model, multiple modifications in a modification set can be performed. In this case, the methodology is based on the author's solution and [16-21].

For the development and validation of the methodology, a simple beam model has been used. An exemplary supporting structure has been tested and calculated using FEM for input redundancy. The results of the modal analysis of the considered beam are presented in Table 1 . The tests were carried out for free suspension with modal hammer. The answer has been recorded with accelerometer. The test was performed for one direction of vibration ( $X$ direction, Figure 5 ). The results in 
TABLE 1: Considered beam mode shapes and natural frequencies for three first modes. Comparison of FEM and experiment results.

$\begin{array}{ccc}\text { 1st frequency, } 113 \mathrm{~Hz} & \text { 2nd frequency, } 307 \mathrm{~Hz} & 3 \mathrm{rd} \text { frequency, } 593 \mathrm{~Hz} \\ \text { 1st frequency, } 115.2 \mathrm{~Hz} \\ \text { Damping, } 0.9153 \%\end{array}$

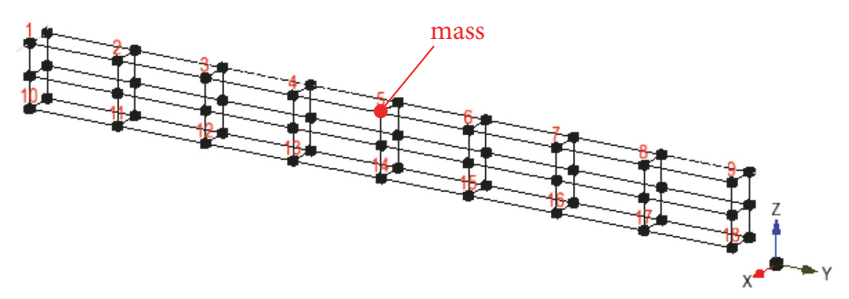

FIGURE 5: Tested beam with modal points and marked point with additional mass.

the table are compiled with the results from FEM model [22] and they are very compatible.

The structural dynamic modification described widely among others in $[19,20]$ has been applied for the results obtained in the experimental modal analysis. In the case being analysed, additional mass of different values has been added in point 5 (Figure 5).

Applied changes have resulted in change in beam modal parameters. Figure 6 includes exemplary FRF plots that show the eigenmodes changes for two different masses $\left(m_{1}<\right.$ $m_{2}$ ) applied in point 5 (Figure 5). Changes are logical and comply with the laws of physics [23]. For each extra mass, the frequency of the character has been added in the knot and it does not change. The remaining frequencies change. For higher frequencies, the sensitivity for changes is also higher.

\section{Results and Discussion}

3.1. Modal Analysis of Prototype Machine Tool Body. Based on experimental studies, the first characters and the frequency values of eigenmodes were identified. Obtained results are summarised below with the results of the FEM analysis of the milling centre stand body. Table 2 shows the comparison of results obtained from FEM and the experimental model for individual modal characters. Table 3 includes the comparison of the mode shapes, visualisations obtained in FEM and visualisations of the mode shapes from the experiment, generated in the Machine Tools Integrated Research in Industry Conditions System (MTIRICS) as one of its outputs. As can be observed, the analysis of obtained results taking into account the nonadjusted ones with experimental data FEM model high results coverage (FEM-experiment) has been achieved. Most of the designated modal vibrations represent bending vibrations. Modes from the second to the fourth represent also twisting vibrations that have not met the results captured in FEM. That can be one of the reasons of a noticed significantly lower coverage between FEM and experiment results. A difference in results of above $6 \%$ can be considered as acceptable. Another thing noticed only during the experiment is that the mill base and the mill stand vibrate in contra phases, which causes intensification of the set modal vibration frequency.

3.2. Model-Based Methodology Application. An exemplary analysis gives an insight into the applicability of this technique to prediction of prototype structure parameters and can be used in machine tool construction. Figure 7 shows an example of a modal structural modification of machine tool body in the Modal VIEW software $[24,25]$. The implantation of the spindle was carried out by inserting the mass in the points indicated in the drawing of the structure.

Applied modification results in a change of the modal parameters of the milling centre. Figure 8 illustrates an exemplary FRF showing the change in the frequency of the internal vibration for two different masses distributed in the points (Figure 7).

Table 4 shows the influence of the additional masses (where $m_{2}>m_{1}$ ) on the own frequencies of the machine tool body. The "no load" results are consistent with the results (and taken from) of Table 1; from there comes also the modified modal model. It should be emphasized that, due to the proven reliability of the dynamic parameters obtained from experimental modal analysis and FEM analysis, the modification can be based on a modal model calculated from experimental data and derived from FEM.

Analogical predictors of modal parameters for the body can be predicted by predicting the characteristics of the machine before assembly of the headstock. It can be seen that the first frequency decreases with increasing the loading mass.

\section{Conclusions}

Considering comparison of the results obtained in experiment and FEM, frequencies related to first, fifth, and seventh 
TABLE 2: Mode shapes and natural frequencies for seven first modes. Comparison of FEM and experiment results.

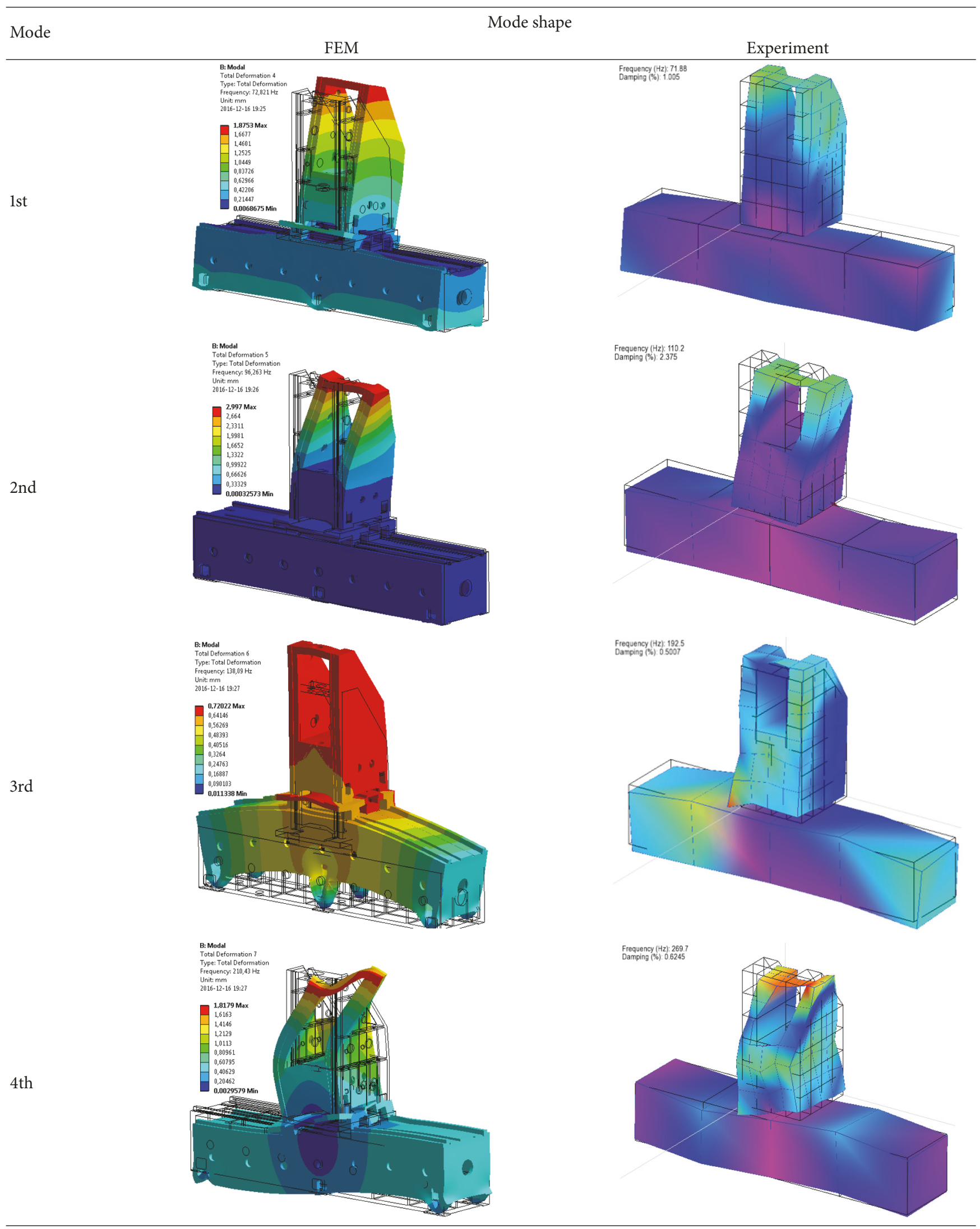


TABLE 2: Continued.

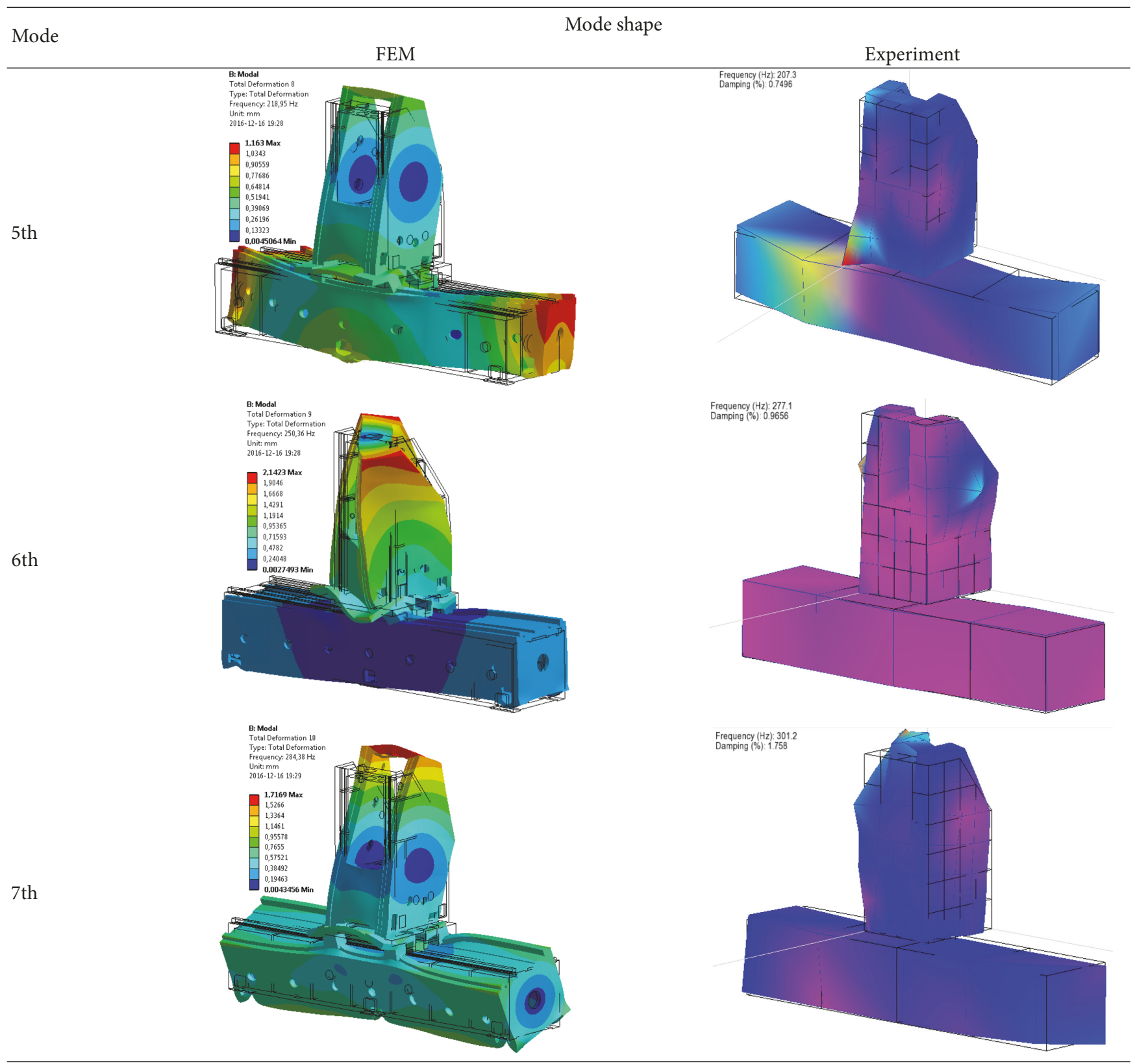

TABLE 3: Modal frequencies for seven first modes. Comparison of FEM and experiment results.

\begin{tabular}{lccc}
\hline Mode & FEM & Frequency $[\mathrm{Hz}]$ & Difference $[\%]$ \\
\hline 1st & 72.821 & 71.88 & 1.3 \\
2nd & 96.263 & 110.2 & 14.4 \\
3rd & 138.09 & 192.5 & 39.4 \\
4th & 210.43 & 269.7 & 28.1 \\
5th & 218.95 & 207.3 & 5.6 \\
6th & 250.36 & 277.1 & 10.6 \\
7th & 284.38 & 301.2 & 5.9 \\
\hline
\end{tabular}




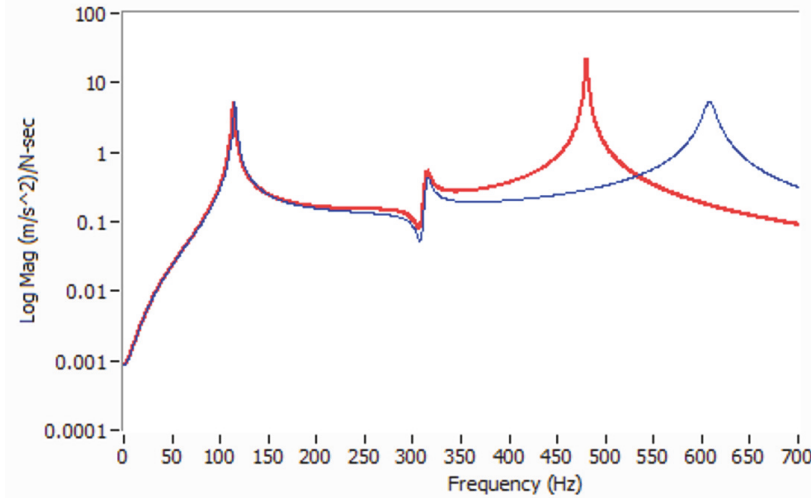

(a)

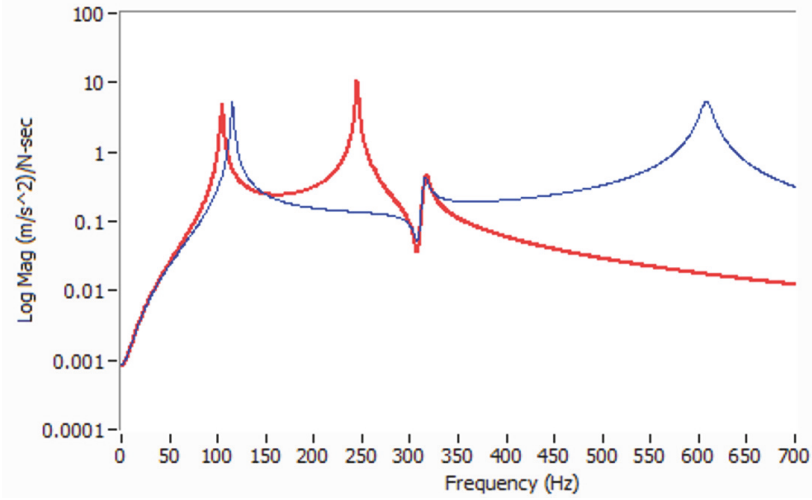

(b)

FIGURE 6: FRF plot for structural dynamic modification. Blue plot: input DOF $1 X$ (force applied in point 1 in $X$ direction); red plot: output DOF $5 X$ (output measured in point 5 in $X$ direction) for two different masses. (a) Lower mass $m_{1}$; (b) higher mass $m_{2}$.

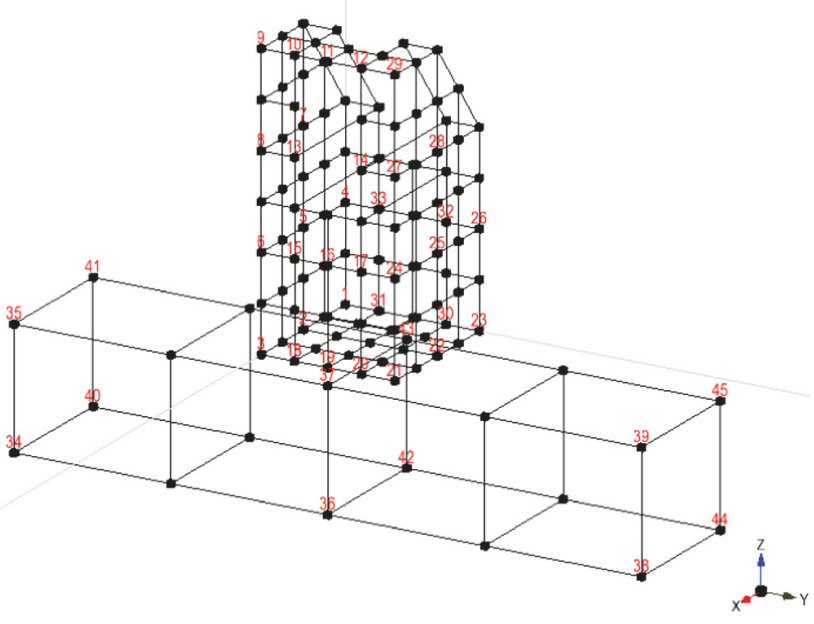

(a)

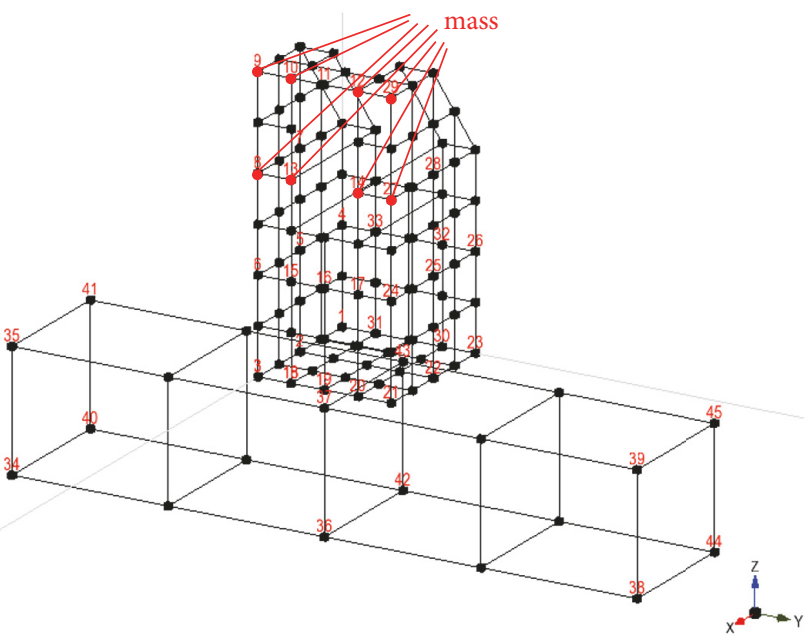

(b)

FIGURE 7: Tested structure with marked modal points (a) and additional mass in modal structural modification of machine tool body (b).

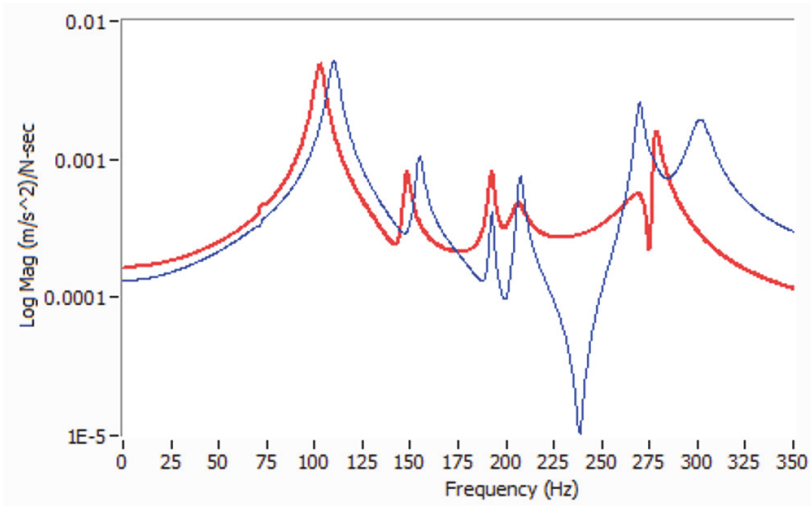

(a)

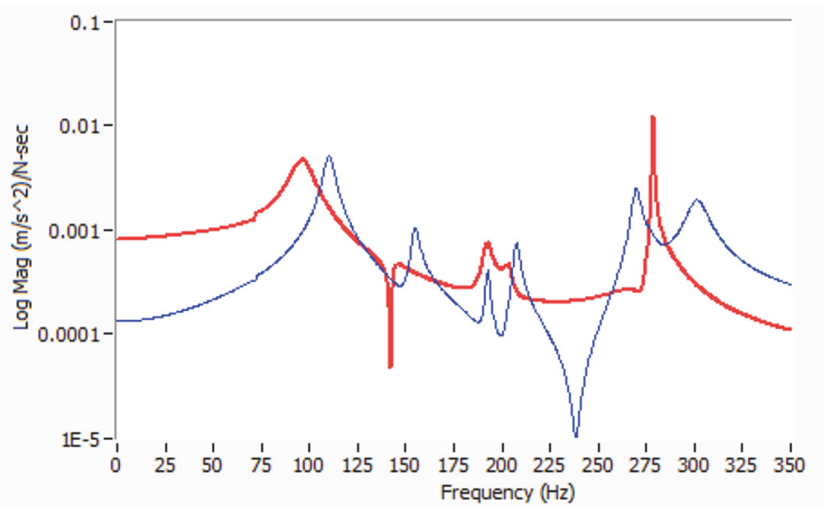

(b)

FIGURE 8: FRF plot for structural dynamic modification. Blue plot: input DOF 11Y (force applied in point 11 in $Y$ direction); red plot: output DOF 44Y (output measured in point 44 in $Y$ direction), for two different masses. (a) Lower mass $m_{1}$; (b) higher mass $m_{2}$. 
TABLE 4: Modal frequencies for eight first modes. Comparison of achieved results.

\begin{tabular}{lccc}
\hline Mode & Without additional mass & $\begin{array}{c}\text { Frequency }[\mathrm{Hz}] \\
\text { With additional mass } m_{1}\end{array}$ & With additional mass $m_{2}$ \\
\hline 1st & 71.88 & 71.61 & 63.32 \\
2nd & 110.20 & 103.10 & 71.93 \\
3rd & 154.70 & 148.30 & 96.71 \\
4th & 192.50 & 177.00 & 142.80 \\
5th & 207.30 & 192.80 & 192.50 \\
6th & 269.70 & 205.90 & 203.90 \\
7th & 277.10 & 274.10 & 278.10 \\
8th & 301.20 & 278.00 & 278.60 \\
\hline
\end{tabular}

modes have high compatibility (difference between FEM and experiment lower than 6\%) (Table 2). As has been observed in other researches [26], the difference between FEM and experiment is rising up for the higher frequencies and the modal frequencies are higher for the experiment that is connected with inaccurate damping coefficients in FEM. In the case analysed in this paper, a satisfactory relation of the compared results for the higher frequencies has been observed. Except for this rule, the second, third, and fourth modes have higher frequencies for the experiment; furthermore, a high divergence from the FEM results was observed. As it can be noticed in the modal shapes plots comparison (Table 2), in the second mode, the analysed stand and mill base vibrate in contra phases, which results in an increase in the eigenfrequency of the set (experimental value). In FEM, due to fixed body with the ground, the ground damping has not been taken into account [27]. The more accurate damping in connections between the analysed set parts may result in more accurate FEM results. Inaccurate damping coefficients in FEM, as has been observed, result in lower frequencies in comparison with the experiment. The need to improve the dynamic parameters of newly constructed machines, in particular machines performing machining processes, forces the designers to identify the dynamic characteristics already at the design stage of a construction process. The studies support the use of FEM analyses as their results provide specific information that is useful in the design phase. The results of FEM analyses may be a basis to change the geometry of the structure and thus lead to improved dynamic characteristics before manufacturing the prototypes. As commonly used in the practice testing technique of dynamic properties, modal analysis allows identifying the parameters of the mechanical objects and thereby allows predicting their behaviour as a result of imbalances. For the methodology described in the article concerning the study of machine tool stand body, taking into account the lack of validation of the model, achieved results and compatibility of theoretical and experimental modal analysis are satisfactory. Researches related to the identification of dynamic parameters of machine tools elements are often implemented as simulation studies and/or experimental research. However, due to the high costs of prototyping, generally they are limited to simulation studies.
In study presented in this article, thanks to the machine prototype, it was possible to carry out these studies in a comprehensive manner. Thus, it became possible to assess the quality of the FEM numerical model. It can be a redundant and simultaneously a very accurate input for the presented modal parameters modification using structural dynamic modification techniques methodology.

The capabilities offered by software using structural dynamic modification $[19,20,24,25]$ provide great measurement and computational capabilities. Based on experimental data, a numerical model representing the dynamic properties of the real object can be developed, which in the analysed case constitutes the bodies of the machine tool. It is also possible to modify the numerical model and quickly check how the change affects the dynamics of the object. It is possible to introduce mass or mass distribution into selected points of the model structure to connect the points of the model structure to the elastic damping elements or to use the "add tuned absorber" technique for estimating the elasticabsorbing parameters of the absorber to obtain the desired frequency of the vibration. This significantly influences the cost of the machine prototype and, if necessary, its modification or modernization. It also shortens the time needed to complete them. Considering that the frequency band limits the scope of the proposed modifications, in particular the major modifications should be carried out with care.

In this case, we can talk about hybrid modeling (stage, incomplete), where the prototype consists only of part of the machine and can be carried out for experimental modal analysis. However, the features of the machine are not known due to the lack of a headstock. A further stage of construction can take place with prediction of dynamic features of the machine using the techniques described in this paper.

Another case of using the described techniques is the case of the machine modernization. With modal model, at the design stage, structure of selected machine components can be upgraded adequately to achieve specific characteristics of the dynamics of the whole machine at the design stage. The above-mentioned approach to design can be aided with FEM (FEM as a stage design) or modal model can be developed based on the results of the FEM instead of experiment. In contrast to the modeling using only FEM, application 
of the predicted modification characteristics speeds up the prototyping process and at the same time the cost of design can be reduced.

\section{Conflicts of Interest}

The authors declare that there are no conflicts of interest regarding the publication of this paper.

\section{Acknowledgments}

The publication was cofinanced by the statutory subsidy of the Faculty of Mechanical Engineering of the Silesian University of Technology in 2017/2018.

\section{References}

[1] Y. Altintas, M. Eynian, and H. Onozuka, "Identification of dynamic cutting force coefficients and chatter stability with process damping," CIRP Annals - Manufacturing Technology, vol. 57, no. 1, pp. 371-374, 2008.

[2] J. Kosmol, J. Sliwka, K. Klarecki, W. Mieszczak, and J. Śliwka, "Identification of static and dynamic properties of axle-turning lathe," in Proceedings of the 12th International DAAAM Symposium, Intelligent Manufacturing Automation: Focus on Precision Engineering, Jena, Germany, 2001.

[3] A. Fortunato and A. Ascari, "The virtual design of machining centers for HSM: Towards new integrated tools," Mechatronics, vol. 23, no. 3, pp. 264-278, 2013.

[4] W. Grzesik, "Chapter Five - Modelling and Simulation of Machining Processes and Operations," in Advanced Machining Processes of Metallic Materials, pp. 49-67, Elsevier, Amsterdam, Netherlands, 2008.

[5] K. Lehrich and J. Kosmol, "Trends in the development of machinery and associated technology," in Proceedings of the 14th International research/expert conference, Mediterranean Cruise, S. Ekinović, Y. Uctug, and J. Vivancos, Eds., pp. 45-48, University of Zenica, 2010.

[6] L. Uriarte, M. Zatarain, D. Axinte et al., "Machine tools for large parts," CIRP Annals - Manufacturing Technology, vol. 62, no. 2, pp. 731-750, 2013.

[7] J. Kosmol and P. Wilk, "Comparison of Optimization Methods Based on Primitive Bodies of Machine Tools and Preliminary Design," in Proceedings of the Fourteenth International Conference on Civil, Structural and Environmental Engineering, Cagliari, Italy, September 2013.

[8] J. Kosmol and P. Wilk, "Experimental Verification of a Numerical Model of a Vertical Machining Centre," in Proceedings of the Thirteenth International Conference on Civil, Structural and Environmental Engineering Computing, B. H. V. Topping and Y. Tsompanakis, Eds., Crete, Greece, September 2011.

[9] J. Kosmol, K. Lehrich, P. Wilk, and M. Niedbala, "A New Design Method for Machine Tools Frames using the Finite Element Method and Genetic Algorithms," in Proceedings of the Twelfth International Conference on Civil, Structural and Environmental Engineering Computing, B. H. V. Topping, L. F. Costa Neves, and R. C. Barros, Eds., Madeira, Portugal, September 2009.

[10] M. Wąsik and A. Kolka, "Machining Accuracy Improvement by Compensation of Machine and Workpiece Deformation," Procedia Manufacturing, vol. 11, pp. 2187-2194, 2017.

[11] N. Grossi, L. Sallese, F. Montevecchi, A. Scippa, and G. Campatelli, "Speed-varying Machine Tool Dynamics Identification
Through Chatter Detection and Receptance Coupling," in Proceedings of the 5th CIRP Global Web Conference Research and Innovation for Future Production, 2016, pp. 77-82, grc, October 2016.

[12] H. Cai, B. Luo, X. Mao et al., "A method for identification of machine-tool dynamics under machining," in Proceedings of the 15th CIRP Conference on Modelling of Machining Operations, CMMO 2015, pp. 502-507, deu, June 2015.

[13] M. Rahman and V. C. Venkatesh, "Effect of Clamping Conditions on Chatter Stability and Machining Accuracy," CIRP Annals - Manufacturing Technology, vol. 34, no. 1, pp. 339-342, 1985.

[14] D. M. Abrams and L. Kops, "Effect of Waviness on Normal Contact Stiffness of Machine Tool Joints," CIRP Annals - Manufacturing Technology, vol. 34, no. 1, pp. 327-330, 1985.

[15] A. Jablonski and T. Barszcz, "Validation of vibration measurements for heavy duty machinery diagnostics," Mechanical Systems and Signal Processing, vol. 38, no. 1, pp. 248-263, 2013.

[16] H. Hang, K. Shankar, and J. C. S. Lai, "Effects of distributed structural dynamic modification with additional degrees of freedom on 3D structure," Mechanical Systems and Signal Processing, vol. 24, no. 5, pp. 1349-1368, 2010.

[17] H. Hang, K. Shankar, and J. C. S. Lai, "Effects of distributed structural dynamic modification with reduced degrees of freedom," Mechanical Systems and Signal Processing, vol. 23, no. 7, pp. 2154-2177, 2009.

[18] H. Hang, K. Shankar, and J. C. S. Lai, "Prediction of the effects on dynamic response due to distributed structural modification with additional degrees of freedom," Mechanical Systems and Signal Processing, vol. 22, no. 8, pp. 1809-1825, 2008.

[19] A. Sestieri and W. D'Ambrogio, "Structural dynamic modifications," in Encyclopedia of Vibration, S. Braun, Ed., pp. 1253-1264, Elsevier, Oxford, UK, 2001.

[20] P. Avitabile, "Twenty years of structural dynamic modification - A review," S V Sound and Vibration, vol. 37, no. 1, pp. 14-27, 2003.

[21] D. Li, Q. Zhou, G. Chen, and Y. Li, "Structural dynamic reanalysis method for transonic aeroelastic analysis with global structural modifications," Journal of Fluids and Structures, vol. 74, pp. 306-320, 2017.

[22] P. Calka and K. Lis, "Eksperymentalna analiza modalna profilu stalowego wypelnionego polimerobetonem," STAL Metale \& Nowe Technologie, 2017.

[23] X. Mao, B. Luo, B. Li, H. Cai, H. Liu, and F. Pen, "An approach for measuring the FRF of machine tool structure without knowing any input force," The International Journal of Machine Tools and Manufacture, vol. 86, pp. 62-67, 2014.

[24] LMS CADA-PC user manual, LMS, Leuven, 1994.

[25] ModalVIEW Operating tutorial R2, 2012, http://absignal.com.

[26] F. J. Herrada, J. García-Martínez, A. Fraile, L. K. H. Hermanns, and F. J. Montáns, "A method for performing efficient parametric dynamic analyses in large finite element models undergoing structural modifications," Engineering Structures, vol. 131, pp. 625-638, 2017.

[27] G. Gazetas, "Analysis of machine foundation vibrations: State of the art," International Journal of Soil Dynamics and Earthquake Engineering, vol. 2, no. 1, pp. 2-42, 1983. 


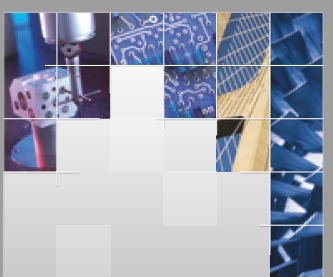

\section{Enfincering}
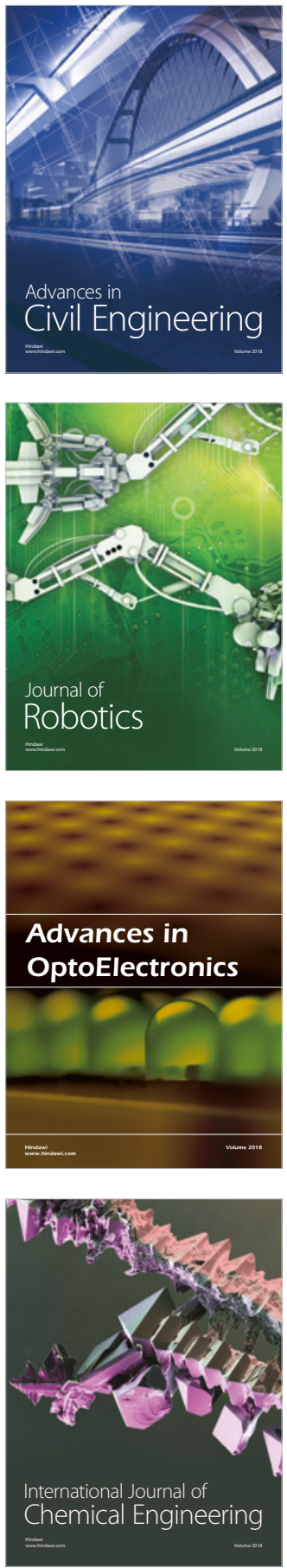

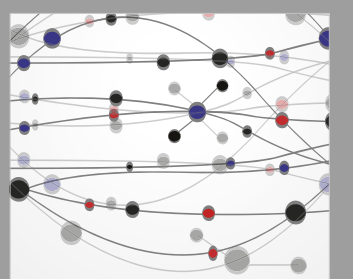

\section{Rotating \\ Machinery}

The Scientific World Journal

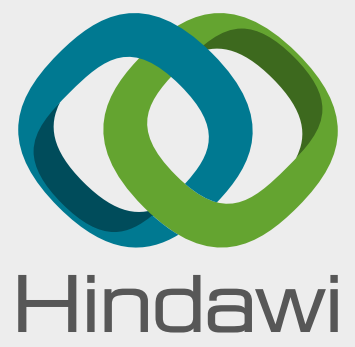

Submit your manuscripts at

www.hindawi.com
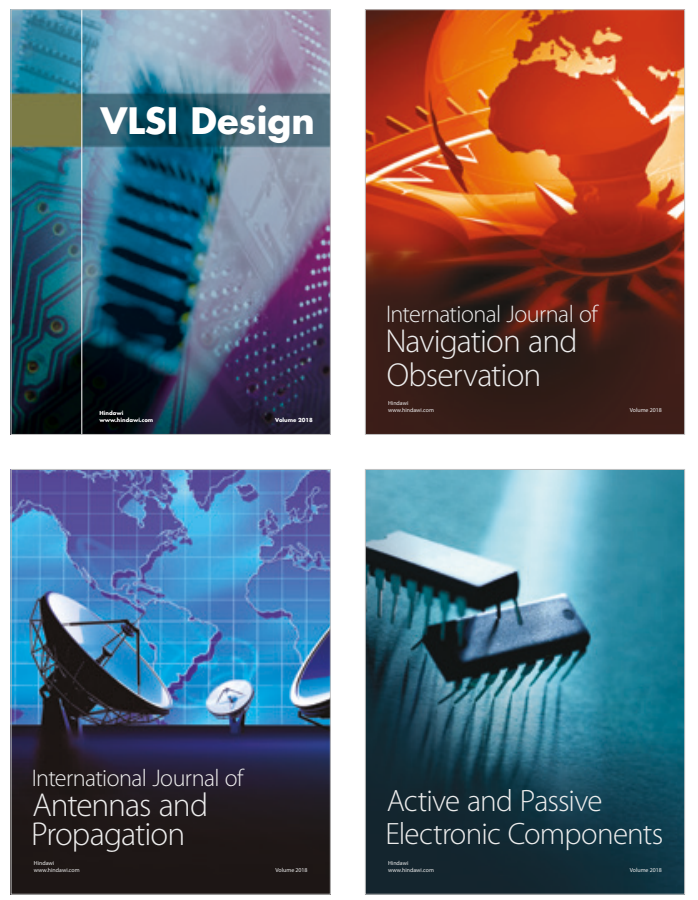
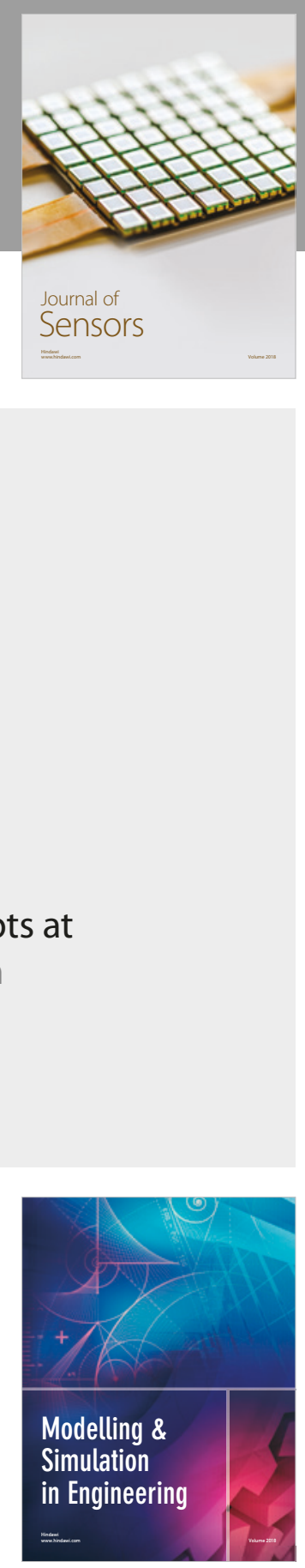

\section{Advances \\ Multimedia}
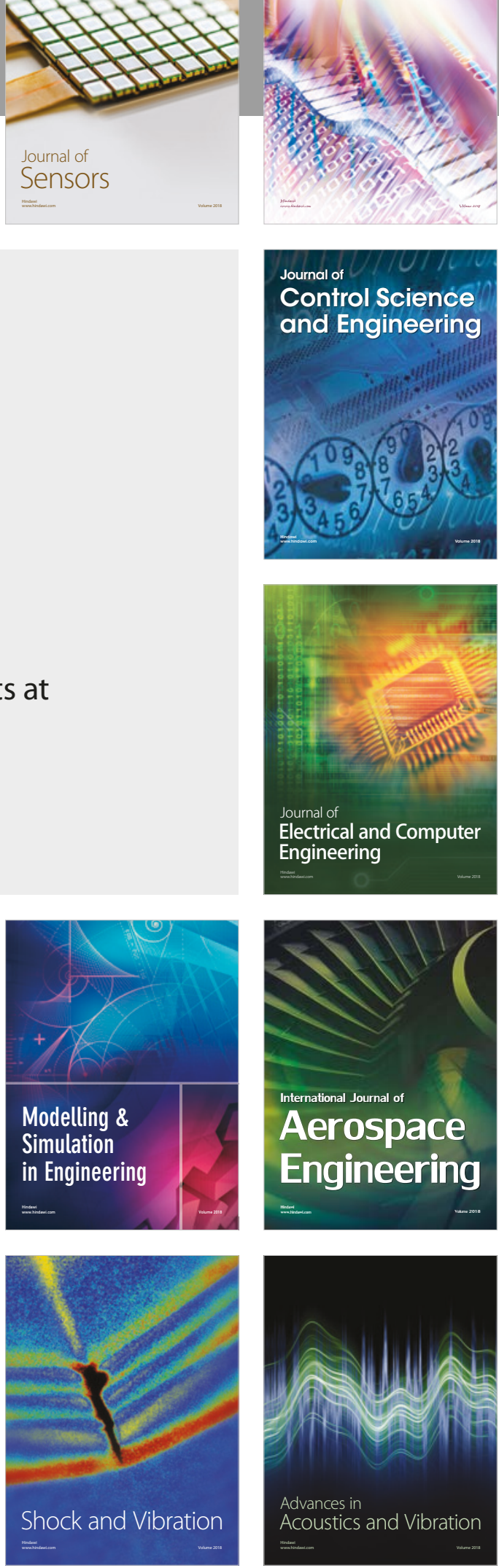